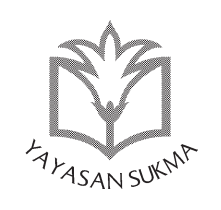

SUKMA: JURNAL PENDIDIKAN

ISSN: 2548-5105

Volume 1 Issue 1, Jan-Jun 2017, hlm. 1-18

\title{
NILAI-NILAI DASAR SUKMA BANGSA
}

\section{Ahmad Baedowi}

Yayasan Sukma Jakarta, Indonesia

email: baedaawi@yahoo.com

\section{Abstrak}

Nama "Sekolah Sukma" pada awalnya dimaksudkan sebagai sekolah unggulan kemanusiaan. Namun, sebagai sekolah baru tak mungkin memiliki keunggulan yang langsung bisa diakui oleh masyarakat, maka kata Sukma disepakati untuk dikembalikan pada arti awalnya, yaitu semangat, spirit, ruh atau jiwa bagi sekolah yang kemudian dikenal sebagai Sekolah Sukma Bangsa (SSB). Dari segi penamaan, selain kata keunggulan, juga terkandung kata kemanusiaan. Dua kata dasar inilah, Sukma dan Kemanusiaan, kemudian dijadikan pintu masuk untuk meletakkan nilai-nilai dasar SSB sebagai penanda yang membedakannya dari sekolah-sekolah lainnya, tidak hanya di Aceh, tetapi juga di Indonesia. Nilai-nilai dasar Sukma Bangsa yang 
dijadikan pedoman pengelolaan SSB bertumpu pada keyakinan bahwa kapasitas guru adalah yang utama (teacher supremacy) dan pertama yang harus dipikirkan, direncanakan, dikembangkan dan dilaksanakan. Kedua adalah nilai dasar tentang kesetaraan kondisi bagi seluruh siswa. Prinsip ini penting agar sekolah menjadi ajang peletakan nilai-nilai toleransi dan demokrasitasi paling awal sebelum mereke kembali ke masyarakat. Nilai dasar ketiga bertumpu pada upaya membangun partisipasi masyarakat dalam rangka menumbuhkan kesadaran pentingnya investasi dan pembiayaan pendidikan anak-anak yang dipikirkan secara bersama. Terakhir adalah praktek menerapkan Rancangan Anggaran Pendapatan dan Belanja Sekolah (RAPBS) secara transparan dan terbuka yang melibatkan semua pemangku kepentingan (stakeholders) pendidikan.

Kata Kunci: sekolah unggulan; Sukma; kemanusiaan; teacher supremacy; pembiayaan pendidikan; transpransi RAPBS

"History is a race between education and catastrophe."

(HG Wells)

\section{Pendahuluan}

Penting untuk menjelaskan kembali kepada setiap orang tentang peran sentral pendidikan terhadap masa depan suatu bangsa. Sejarah kemajuan suatu bangsa sebenarnya sering dipertaruhkan oleh siapa saja yang merasa bahwa investasi dalam bidang pendidikan tidak penting. Tetapi, tidak jarang efek dari pendidikan juga bisa membuat sebuah negara merasa paling benar dan paling beradab sehingga semua jenis ilmu dan pengetahuan dikerahkan untuk menguasai orang lain demi mempertahankan reputasinya sebagai negara maju.

"As is the state, so is the school" (sebagaimana negara, seperti itulah sekolah) atau "What you want in the state, you must put into 
the school" (apa yang anda inginkan dalam negara, harus anda masukkan ke sekolah) adalah ungkapan para penggagas korelasi antara demokratisasi dan situasi pendidikan suatu negara. Karena itu peran negara bisa sangat kuat terhadap arah dan visi pendidikan suatu negara, sehingga implikasi praktisnya akan menjadikan semua bangunan kebutuhan pembelajaran menjadi sangat formal. Padahal totalitas pendidikan harus meliputi semua jenis dan pendekatan pengajaran, baik formal, informal maupun non-formal. Di Indonesia, dominasi negara terhadap problematika pendidikan sangat kuat, terlihat dari cara bagaimana negara membingkainya dalam bentuk kebijakan. Meskipun visi pendidikan nasional adalah menjadikan pendidikan sebagai sarana mewujudkan masyarakat yang cerdas dan bertakwa kepada Tuhan Yang Maha Esa, tetapi pendekatan yang digunakan negara dalam merumuskan kebijakan tentang sistem pendidikan nasional terlihat sekali masih sangat formalistik.

Hasil riset di beberapa negara menunjukkan bahwa persoalan pendidikan lebih sering dikemas dalam balutan politik secara serampangan, sehingga ikut menumbuhkan situasi yang tidak seimbang dan tidak konsisten menyangkut relasi antara sesama birokrat, politisi, dan masyarakat. Meskipun dalam delapan tahun terakhir ini kita banyak menghasilkan peraturan dan perundangan mengenai pendidikan, tetapi dalam praktiknya terjadi banyak overlapping dan kesalahan dalam implementasi program-program pendidikan (Gary K. Clabaugh dan Edward G. Rozyki, 2006). Inefektifitas akan terjadi lagi di Indonesia dalam sepuluh tahun ke depan, jika dari sekarang baik para politisi, birokrat dan masyarakat tidak memiliki konsensus ke mana biduk pendidikan akan diarahkan.

Sekolah Sukma Bangsa lahir dari kepedulian kelompok media group yang berhasil mengumpulkan dana melalui program Indonesia Menangis di Metro TV. Gempa bumi tektonik berkekuatan 8,5 SR yang berpusat di Samudra India atau di laut berjarak sekitar $149 \mathrm{~km}$ selatan kota Meulaboh, Nanggroe Aceh Darussalam yang disertai gelombang pasang tsunami menyapu beberapa wilayah lepas pantai di Indonesia (Aceh dan Sumatera 
Utara), Sri Lanka, India, Bangladesh, Malaysia, Maladewa dan Thailand. Menurut data Departemen Sosial, korban gempa dan tsunami di Aceh mencapai angka 105.262 orang. Sedangkan total luka-luka sebanyak 124.057 orang, diperkirakan 100.000-an diantaranya dialami rakyat Aceh dan Sumatera Utara. Kisah suram 10 tahun silam yang terjadi di penghujung tahun 2004 seperti menyiratkan rencana besar Tuhan untuk membuka mata hati Aceh dan masyarakat dunia untuk bersatu atas nama kemanusiaan.

Selain gempa dan tsunami, Aceh juga dikenal sebagai daerah konflik yang berkepanjangan antara Gerakan Aceh Merdeka (GAM) dengan pemerintah pusat. Adanya tsunami membuat nurani manusia luluh dan menyadari tentang kefanaan dan pentingnya manusia Indonesia bersatu kembali. Inilah makna terdalam tsunami secara teologis, di mana ketidak-berdayaan memunculkan harapan baru, terutama membangun semangat anak-anak untuk memperoleh proses pendidikan berkualitas dan menyenangkan.

Dalam konteks inilah Sekolah Sukma Bangsa (SSB) hadir, yaitu sebagai antitesa dari kemalangan dan keputus-asaan menuju semangat dan harapan baru. SSB tumbuh dan berkembang menjadi sebuah lembaga yang hari ini telah memperoleh kepercayaan besar dan luar biasa dari masyarakat Aceh. Tak banyak yayasan atau lembaga donor pasca tsunami yang bertahan lebih dari dua tahun di Aceh. Yayasan Sukma dengan SSB adalah anomaly karena niat untuk membuat sekolah lahir dari kesungguhan yang menginginkan anak-anak Aceh cerdas dan berakhlak mulia.

\section{Teacher Supremacy}

Nilai dasar pertama dari pendirian SSB adalah keyakinan bahwa setiap sekolah harus memiliki guru yang benar dan terlatih dengan baik. Salah satu kekuatan SSB terletak pada model pengembangan kapasitas guru yang konsisten dan mengikuti alur visi dan misi sekolah yang jelas dan terukur. Para guru dan penge- 
lola SSB selalu memiliki ide dan kreativitas yang berbeda dengan sekolah kebanyakan, terutama dengan mengombinasi pendekatan gaya dayah (pesantren) dengan pendidikan modern. Dengan inspirasi dan proses belajar secara natural dari buku Peter Senge, A School that Learn (2004), SSB tumbuh dan berkembang di luar dugaan siapa pun karena di dalamnya telah terbangun secara solid komunitas belajar (learning communities) yang sadar akan pentingnya masa depan anak-anak.

SSB seakan tak pernah lelah untuk terus berinovasi dalam menjaga keseimbangan antara ide-ide kontemporer di bidang pendidikan dengan regulasi yang telah dibakukan ke dalam blueprint dan statuta sekolah. Sepengetahuan saya tak banyak sekolah di Indonesia yang memiliki cetak biru (blueprint) yang memuat prinsip-prinsip belajar secara holistik serta statuta sekolah yang mampu mengatur ritme dan irama dari aliran emosional komunitas sekolah secara beradab dan manusiawi. Bukan hanya itu, selain dokomen tertulis, SSB juga secara kreatif mampu mengembangkan teknologi dan informasi ke dalam struktur belajar-mengajar secara efisien.

Salah satu contoh bagaimana teknologi dan informasi secara sadar digunakan SSB untuk meningkatkan kualitas proses belajar-mengajar adalah implementasi sistem informasi sekolah terpadu online (SISTO). Bahkan jauh sebelum masyarakat meributkan skema penilaian atau evaluasi yang adil terhadap siswa dalam kurikulum 2013 (K-13), SISTO di SSB sudah melakukan proses evaluasi berkeadilan bukan hanya terhadap siswa, tetapi juga penilaian terhadap performa guru dan kepala sekolah. Artinya, penggunaan SISTO sejak tahun 2006 di SSB telah melampuai kemampuan rata-rata sekolah di Aceh pada khususnya, dan Indonesia pada umumnya.

Semua hasil dan capaian SSB hingga saat ini tak mungkin berhasil dan bertahan tanpa pola pengembangan kapasitas guru yang benar dan memadai. Dari mulai keberanian untuk melakukan proses pertukaran guru dengan sekolah-sekolah ternama di Jakarta, Bandung dan Yogyakarta pada awal sekolah beroperasi, 
hingga akhirnya saat ini SSB dengan kemampuannya sendiri sedang bekerja sama dengan Finland University untuk mendidik 30 orang guru dalam Comission Master Degree Program for Teacher Development. Nilai dasar pertama ini jarang sekali disadari sebagai kebutuhan utama pengembangan lembaga pendidikan.

Dari keyakinan terhadap nilai dasar pertama ini, hasilnya dapat dilihat dari perkembangan SSB, yaitu meningkatkan kemampuan intelektual teman-teman yang terlibat di dalamnya. Tak terbayangkan oleh saya sebelumnya, setalah 10 tahun mengelola sekolah, saya dan teman-teman lainnya mampu menuliskan pengalaman kami secara apa adanya berdasarkan pengalaman masing-masing ke dalam 5 buku. Tak banyak kesempatan seperti ini dimiliki oleh siapa pun yang teribat dalam proses pendidikan. Kalaupun ada biasanya itu merupakan inisiatif pribadi dan bersifat individual, tetapi di SSB saya melihat ada kebersamaan luar biasa ketika mereka menulis, dan hasilnya menurut saya patut diapresiasi oleh siapa pun yang peduli dengan peningkatan kualitas pendidikan di tanah air.

\section{Kesetaraan Kondisi}

Nilai dasar kedua dari SSB menurut saya adalah cara pandang pengelola sekolah terhadap input atau siswa yang memerlukan kesetaraan kondisi. Bayangkan, jika anak-anak korban tsunami dan konflik saat itu diperlakukan sama dengan cara kita menerima siswa di sekolah lain, maka sudut pandang kesetaraan kondisi sebagai nilai dasar kedua SSB tak pernah ada. Kami belajar bukan hanya dari kasus tsunami dan konflik di Aceh, tetapi soal anak-anak yang akan menjadi siswa SSB juga bisa berkaca pada pengalaman negara sebesar Amerika.

Ada banyak anak yang kurang beruntung dalam hal pendidikan. Mereka gagal bukan hanya karena faktor sistem yang tidak menempatkan anak sebagai pusat perhatian, tetapi banyak juga kegagalan dibentuk oleh kelemahan guru dan manajemen sekolah yang tidak becus dalam mendidik. Ada banyak juga anak 
yang berhasil, bahkan untuk contoh yang satu ini lebih banyak datang dari sisi kemampuan anak yang memperoleh dukungan, baik secara finansial maupun moral, dari orangtua, guru dan lingkungan sekolah yang sehat.

Pendidikan, dalam diaspora yang sangat luas, memang memberi banyak kesempatan dan peluang bagi masa depan anak-anak. Lihatlah kasus yang menimpa seorang Greg Mortenson. Melalui dua buku kuncinya yaitu Three Cups of Tea dan Stones into School, sesungguhnya ia sedang ingin membuktikan bahwa ada cara lain untuk membangun hubungan ke arah yang lebih baik daripada perang, yaitu membangun sekolah dan memberi kesempatan anak-anak yang kurang beruntung akibat konflik berkepanjangan di Afghanistan dan Pakistan.

Di Amerika kita mendapati kasus yang menimpa seorang anak bernama Khadijah Williams. Karena keluarganya termasuk katagori gelandangan (homeless), Khadijah sangat akrab dengan lingkungan tempat tinggal di lokasi tempat-tempat sampah, shelter-shelter, lapangan dan taman-taman umum yang terbuka dari Los Angeles ke San Diego, dari San Fransisco hingga ke Orange County. Selama kurang lebih 12 tahun, Khadijah telah bersekolah di 12 sekolah berbeda karena hidupnya yang berpindah-pindah.

Dengan ditemani oleh Ibu dan adik perempuannya, Khadijah Williams tahu persis bagaimana rasanya harus tetap bersekolah dengan kondisi serba minim, sementara diusianya yang masih belia dia juga menjumpai fakta-fakta tentang kerasnya kehidupan para mucikari dan PSK di jalan-jalan, serta para pengedar narkoba yang selalu mengancam kesehatan berpikir dan jiwanya sekaligus.

Akhir Juni 2009 lalu dia lulus dari Jefferson High School di Los Angeles pada urutan ke 4 di kelasnya. Setelah dia dan sekolahnya mengirimkan profil dan lamaran ke banyak perguruan tinggi, 20 perguruan tinggi bersedia menerimanya sebagai mahasiswa penerima beasiswa penuh, di mana pilihan akhirnya dia jatuhkan ke Harvard University yang sangat bergengsi itu. Apa yang dilakukan Khadijah membuat semua orang terperangah, 
bahkan teman-teman di sekolahnya pun tak menyangka kalo dia datang dari lingkungan keluarga gelandangan.

Dua contoh di atas menunjukkan bahwa sebarapun gawatpun kondisi sebuah masyarakat, jika sistem yang dipilihnya benar, maka persoalan akses bisa diatasi secara baik. Jika kesetaraan adalah fitrah yang secara normatif merupakan kebutuhan manusia secara keseluruhan, maka benar adanya jika konstitusi kita (UUD 1945) telah menyebutnya secara kasat mata. Karena itu ketika Undang-undang Nomor 9 Tahun 2009 tentang Badan Hukum Pendidikan (BHP) dibatalkan oleh Mahkamah Konstitusi (MK), maka harapan untuk menegakkan kesetaraan dalam rangka mencerdaskan kehidupan bangsa dan menjamin sepenuhnya hak setiap warga negara untuk memperoleh pendidikan adalah sebuah keniscayaan.

Kasus UU BHP merupakan kesalahan fundamental birokrasi pendidikan kita dalam memahami dan memaknai gagasan tentang kesetaraan yang berorientasi hanya kepada akses dan partisipasi (Lynch, 2000). Padahal sejatinya kesetaraan (equality) bukan saja harus dilihat dari tujuan dan proses pendidikan semata, tetapi juga harus mempertimbangkan kondisi sosial, politik, ekonomi, budaya dan agama. Hanya dengan cara pandang seperti inilah kemudian kita dapat merumuskan gagasan tentang kesetaraan kondisi (equality of condition) sebagai pendekatan dalam merumuskan kebijakan pendidikan yang pro pada kebutuhan publik.

Baker (2004) dalam Equality: From Theory to Action memberi banyak inspirasi dalam menafsirkan makna kesetaraan. Baginya kesetaraan kondisi (equality of condition) jauh lebih penting dari kesetaraan dalam konteks akses dan partisipasi. Dalam equality of condition fokus kita berikan bukan hanya terhadap tujuan dan proses (purposes and process) pendidikan itu sendiri, tetapi juga berkaitan dengan kesetaraan terhadap sumberdaya (equality of resources), kesetaraan dalam pengakuan dan penghargaan (respect and recognition), kesetaraan dalam kekuasaan (equality of power), dan kesetaraan dalam kepedulian, 
solidaritas dan cinta (love, care and solidarity). Semua jenis kesetaraan ini jelas membutuhkan kecerdasan birokrasi pendidikan kita untuk merealisasikannya.

Kesetaraan sumberdaya harus dibuktikan dengan penciptaan sistem pendidikan yang lebih terbuka dan non-diskriminatif, sedangkan kesetaraan dalam pengakuan dan respek harus diciptakan bukan hanya dengan membangun budaya sekolah yang menghargai perbedaan, tetapi juga harus diekspresikan secara tertulis dalam skema pedagogis dan kurikulum yang memadai. Sementara kesetaraan kekuasaan harus dilihat dalam relasi guru-siswa yang semakin peduli dengan proses belajar-mengajar yang demokratis, sehingga implikasi dari pandangan ini akan membawa keterbukaan pandangan untuk saling menghargai posisi dan peran masing-masing dalam proses belajar.

Demokratisasi dalam dunia pendidikan merupakan ruang segar yang harus diciptakan, sehingga antara siswa dan guru memiliki kebebasan untuk menyatakan perasaan dan pendapat mereka. Dalam konteks ini, kesetaraan kondisi-kondisi tersebut penting untuk dilakukan terlebih dahulu oleh penyelenggara pendidikan kita, sebelum mekanisme evaluasi dan monitoring pendidikan seperti ujian nasional diberlakukan secara massif hanya untuk menguji sesuatu yang kurang prasyarat kondisinya.

\section{Partisipasi Masyarakat dan Pembiayaan Pendidikan}

Ini adalah nilai dasar ketiga ketika mengelola SSB, yaitu bagaimana manajemen sekolah harus selalu memikirkan exit strategy yang baik karena SSB memiliki stigma yang luar biasa berat sebagai sekolah gratis dan untuk korban tsunami dan konflik. Kita bisa mengingat ketika dua tahun pertama sekolah ini beroperasi, tak sedikit tantangan yang datang dari semua stakeholders kependidikan. Bahkan masyarakat dan orangtua terlihat nyinyir dengan SSB hanya karena kebanyakan gurunya pada waktu itu 45\% memang berasal dari tanah Jawa. Sebagai daerah bekas konflik, orang asing seperti guru-guru dianggap sebagai penjajahan model baru. Mereka hampir tak bisa melihat manfaat 
sekolah bagi masa depan anak-anak mereka. Tetapi setelah 11 tahun, jika orangtua ditanya bahwa SSB akan diserahkan pengelolaannya kepada pemerintah, 99\% orangtua dan masyarakat menolak, juga jika sekolah ada yang mengganggu masyarakat sendiri yang membela SSB. Prinsip Community Based Learning (CBL) yang kami lakukan tanpa kenal rasa lelah berbuah manis, karena kesadaran orangtua dan masyarakat terhadap kualitas pendidikan yang baik dan benar merupakan jaminan masa depan anak-anak mereka, dan ini ditunjukkan dengan meningkatnya tingkat partisipasi masyarakat terhadap operasional sekolah.

Portfolio tentang CBL banyak mengambil bentuk dari beberapa eksemplar prinsip parenting education, di mana bukan hanya sekolah yang memiliki kewajiban untuk mengingatkan masyarakat, tetapi pada waktu yang bersamaan juga memberikan kepercayaan kepada masyarakat untuk mengusulkan bentukbentuk relasi dan komunikasi antara sekolah dan orangtua yang relevan dengan kebutuhan anak-anak mereka.

Dalam teori sosiologi kependidikan, ukuran manfaat sosial (social benefits), beberapa di antaranya manfaat pasar, yang relevan dengan berapa banyak total investasi dalam pendidikan yang harus dibiayai publik merupakan ukuran standar seberapa besar bentuk keterlibatan publik terhadap pendidikan. Jika bentuk kesadaran ini hidup dan bertumbuh di masyarakat, maka manfaat sosial pendidikan untuk orang lain dan generasi mendatang pasti memiliki jaminan masa depan yang cemerlang. Pertanyaannya adalah, berapa persen kira-kira total partisipasi orangtua terhadap pendidikan anak-anak mereka?

Angka perkiraan partisipasi orangtua/masyarakat terhadap dunia pendidikan memang berbeda antara satu propinsi dengan lainnya. Di Aceh, menurut sebuah survey, orangtua dan masyarakat hanya mengeluarkan $15-20 \%$ dari pendapatan kotor per-bulan untuk biaya pendidikan anak-anak mereka. Angka ini cukup moderat, mengingat income perkapita masyarakat kita memang masih kecil dan spending lebih banyak dikonsentrasikan kepada hal-hal yang bersifat konsumtif. Dengan kondisi ini 
akhirnya negara berusaha memenuhi kebutuhan pembiayaan pendidikan masyarakat melalui APBN yang jumlah totalnya mencapai angka $20 \%$.

Kajian tentang pembiayaan sekolah (school funding) menjadi relevan mengingat sistem pendidikan kita belum menganut asas pembiayaan sekolah secara integral yang berorientasi pada pengembangan aspek kualitas sebagai target pembiayaan sekolah. Isu pembiayaan sekolah bermutu (school quality funding) masih dihitung secara minimal, yaitu menyangkut besaran subsidi dari pemerintah untuk tiap siswa pada setiap tingkat satuan pendidkan. Contoh dari kebijakan ini adalah bagaimana Dana BOS dihitung.

Perdebatan yang ramai dibicarakan oleh para praktisi, birokrat dan politisi di sekitar pembiayaan pendidikan pun baru menyentuh aspek kebutuhan siswa sebagai unit analisnya, tetapi belum menghitung kebutuhan institusi sekolah sebagai sebuah pendekatan penjaminan mutu (quality assurance). Agar anggaran pendidikan 20\% yang diamanatkan Undang-undang dapat diserap secara effisien dan transparan, perlu dipikirkan skema-skema pembiayaan pendidikan dengan menggunakan sekolah sebagai unit analisis, bukan lagi kebutuhan siswa.

Beberapa studi tentang dampak kualitas sekolah terhadap capaian akademis siswa mengindikasikan pentingnya menciptakan sebuah budaya sekolah yang sehat secara manajemen, sehingga kebutuhan untuk membangun suasana belajar yang positif dan kondusif dapat dimasukkan kedalam komponen dan indikator pembiayaan pendidikan. Rob Greenwald, dalam "The Effect of School Resources on Student Achievement," Review of Educational Research, (1996), memperlihatkan bahwa strategi pembiayaan pendidikan di tingkat sekolah sangat berpengaruh terhadap capaian siswa. Jika ini yang dilakukan, maka manfaat sosial pendidikan akan lebih dahsyat dari hanya sekedar jargon dan omong kosong.

Beberapa studi tentang dampak kualitas sekolah terhadap capaian akademis siswa mengindikasikan pentingnya mencip- 
takan sebuah budaya sekolah yang sehat secara manajemen. Dalam skema pembiayaan pendidikan, keberhasilan siswa dalam paradigma lama selalu bergantung pada kemampuan finansial orangtua dan karakter psikologis siswa serta menafikan kemampuan manajerial dan budaya sekolah (J.S. Coleman, Equality of Education Opportunity, 1966).

Dalam banyak hal kementerian pendidikan nasional sejauh ini belum mampu membangun sebuah budaya sekolah yang komprehensif dan visioner pada tingkat sekolah, sehingga kebutuhan untuk membangun suasana belajar yang positif dan kondusif tidak jarang belum termasuk dalam komponen dan indikator pembiayaan pendidikan. Padahal jika kita merujuk pada hasil studi lainnya yang dilakukan oleh Rob Greenwald, et.al., dalam "The Effect of School Resources on Student Achievement," Review of Educational Research, (1996), jelas terlihat bahwa strategi pembiayaan pendidikan di tingkat sekolah sangat berpengaruh terhadap capaian siswa.

Beberapa peneliti mencoba untuk memecahkan kebuntuan pembiayaan yang berkaitan dengan pembangunan budaya sekolah sebagai bagian dari kebutuhan pokok sekolah dan berkaitan langsung dengan keberhasilan siswa (student achievement), terutama dengan melihat trend pembiayaan pendidikan secara statistikal. Dengan menggunakan regresi statistikal, terlihat bahwa hubungan capaian akademis siswa dengan budaya sekolah tidak memiliki ikatan yang kuat karena pada prinsipnya siswa memiliki latar belakang budaya dan etnik yang berbeda. Jika hanya mengacu pada indikator kebutuhan siswa per-orang per-tahun, maka rumusan yang muncul biasanya sangat bersifat numerik dan dalam bahasa Eric Hanushek disebut sebagai "production-function studies," di mana dalam beberapa hal terlihat hubungan yang tidak selamanya positif antara semakin besar dana yang digunakan dalam proses pendidikan dengan capaian akademis siswa. Kesimpulannya cukup mengagetkan, "there is no strong or systematic relationship between school expenditures and student performance." (Eric Hanushek, "The Impact of Differential Expenditures on School Performance”, 1989). 


\section{Transparansi RAPBS}

Ketika memulai sekolah di tahun ajaran 2006, optimisme para pengelola Sekolah Sukma Bangsa (SSB) sebenarnya belumlah tinggi. Input sekolah ini adalah anak-anak korban tsunami, korban konflik, yatim piatu dan fakir miskin, bahkan dengan kemampuan akademis di bawah rata-rata anak sekolah di luar Aceh. Tetapi dengan visi ingin menciptakan lingkungan belajar yang positif dan kondusif, seluruh manajemen sekolah mencoba menerapkan beberapa strategi dasar pembiayaan sekolah yang mengacu pada penciptaan budaya sekolah yang aman dan nyaman. Beberapa strategi yang dikembangkan SSB mengacu kepada visi dan misi sekolah sebagai sarana untuk menciptakan lingkungan pendidikan yang positif bagi para siswa. Karena itu sejak awal SSB memperkenalkan budaya moving-class, perluasan makna guru, dan penciptaan jejaring sehingga memungkinkan sekolah untuk memperoleh kritik sekaligus masukan dari para stakeholders.

Strategi pembiayaan moving class ternyata berimplikasi positif terhadap budaya belajar siswa. Guru diwajibkan berkreasi menciptakan sebanyak mungkin class project activities yang tidak hanya berbasis kebutuhan proses belajar-mengajar di kelas melainkan juga di ruang terbuka seperti koridor dan halaman sekolah, perpustakaan, dan lingkungan sekitar. Ketika makna kelas diperluas menjadi keseluruhan sarana-prasarana yang tersedia baik di lingkungan sekolah maupun di luar sekolah, kreativitas dan usulan proses pembelajaran tidak jaranng muncul dari siswa itu sendiri. Karena itu baik guru maupun siswa memiliki hak yang sama untuk mengusulkan sebuah proses pembelajaran, di mana pada tahap akhirnya menjadi kewajiban guru untuk membuat proposal pembiayaan aktifitas kelas tersebut. Setiap guru dengan demikian diharuskan memiliki bukan saja keterampilan lesson design, tetapi juga dituntut untuk dapat menghitung kebutuhan anggaran pada setiap jenis aktifitas kelas yang direncanakannya untuk diusulkan setiap bulan kepada manajemen sekolah.

Perluasan makna guru juga berimplikasi pada kemampuan manajemen sekolah dalam mengidentifikasi sumberdaya 
yang tersedia, baik di lingkungan sekolah maupun di lingkungan komunitas sekolah (stakeholders). Di SSB, konsep guru diperluas bukan saja guru di sekolah, bahkan seorang tukang becak, paramedis puskesmas, polisi, satpam, cleaning service, hingga Bupati adalah sumberdaya guru yang harus diberi kesempatan untuk mengajar di kelas. Kepandaian guru dan murid dalam menentukan 'guest teacher' untuk mata ajar tertentu setiap 2 minggu sekali adalah sebuah proses yang mengasyikkan. Lagilagi kecermatan, kecerdasan dan kreativitas guru dengan siswa dalam mengundang guru tamu harus dituangkan dalam sebuah proposal yang jelas berikut pembiayaannya.

Bahkan dalam beberapa hal setiap bulan manajemen sekolah mengadakan diskusi terbuka tentang perencanaan pembelajaran yang telah tertuang dalam proposal. Pengalaman memaknai perluasan arti guru dengan sendirinya memacu guru itu sendiri untuk pandai membuat proposal dan membaca banyak buku sebagai rujukan proses pembelajaran. Dengan demikian prinsip self-training seperti yang pernah dijabarkan oleh Thomas Gordon dalam Teacher Effectiveness Training menjadi lebih mudah untuk diterapkan.

Sedangkan strategi ketiga, yaitu menciptakan jejaring (networking) dengan seluruh komunitas sekolah (stakeholders) adalah dalam rangka menciptakan partnership antara satu sekolah dengan yang lainnya. Dengan menggunakan pendekatan sebagai pusat sumber belajar bersama (common learning resources center), SSB menawarkan diri kepada sekolah-sekolah sekitar untuk bekerjasama dalam melakukan proses belajar mengajar. Tujuan dari strategi ini adalah dalam rangka memberikan ruang yang luas kepada sekolah untuk mempelajari apa saja yang mereka inginkan dari lingkungan sekitar, di mana akhirnya dapat menopang posisi sekolah sebagai lembaga pendidikan yang mendorong keterlibatan masyarakat dalam proses pendidikan.

Sejauh ini beberapa bentuk kegiatan kerjasama luar sekolah yang telah dilakukan SSB meliputi kegiatan tutoring, mentoring, magang (internship), kunjungan lapangan, kemah siswa, serta pengadaan bahan ajar dan supply pendidikan lainnya yang di- 
fasilitasi melalui koperasi sekolah. Perjalanan masih panjang bagi SSB. Tetapi pengalaman membuat perencanaan pembiayaan pembelajaran yang melibatkan seluruh komponen sekolah paling tidak telah membuka mata SSB untuk berkembang menjadi " $A$ school that's learn". Intinya adalah bagaimana sekolah memiliki keberanian untuk mengelola sumber-sumber pendapatan sekolah secara jujur dan transparan, di mana semua guru, siswa, kepala sekolah, direktur sekolah dan bahkan orangtua siswa berhak untuk mengetahui bagaimana RAPBS dirancang dan diimplementasikan setiap tahunnya.

\section{Tahniah}

Akhirnya, saya ingin mengapresiasi secara jujur kepada semua teman-teman di Yayasan Sukma dan juga teman-teman pengelola manajemen dan guru di Sekolah Sukma Bangsa, bahwa mereka telah mengawal SSB hingga hari ini, di mana tanpa mereka SSB mungkin tetap menjadi sekolah tapi bisa jadi tak memiliki sukma. Kontribusi ide dan gagasan yang kreatif dalam mengelola SSB telah membuktikan bahwa komunitas SSB adalah pejuang bagi tegaknya pendidikan yang berbasis nilai-nilai dan kesadaran keislaman dan keindonesiaan sekaligus. Kepada Pak Surya Paloh dan teman-teman lainnya di Media Group, Anda adalah sandaran moral dan spiritual anak-anak Sukma Bangsa di masa depan. Terimakasih telah memberikan kepercayaan kepada Saya dan kawan-kawan dalam menyemai masa depan anak-anak Aceh yang lebih baik. Bahkan sekarang ditambah dengan tugas yang lebih hebat dan menantang, yaitu menyemai dan mewujudkan mimpi dan cita-cita anak-anak Mindanao yang kurang lebih memiliki nasib yang sama dengan anak-anak Aceh 11 tahun yang lalu.

Kekhawatiran yang masih tersisa adalah masih kuatnya birokrasi pendidikan kita dalam memaksakan kehendak, terutama kebijakan-kebijakan yang tidak didasari oleh riset yang mendalam. Pembaharuan kebijakan pendidikan melalui konsensus antara birokrat dengan komunitas/masyarakat sekolah 
nampaknya harus dijadikan prioritas Mendikbud saat ini. Dan itu harus dijadikan bingkai dialog secara terbuka antar birokrasi di tingkat pusat dan daerah dalam mencermati dan membuat rancangan program pembaharuan pendidikan ke depan. Melacak isu dan mengembangkan pendekatan adalah bagian penting dari sebuah konsensus.

Konsensus dalam bidang pendidikan sangat diperlukan dalam rangka mengetahui harapan (expectations) masyarakat terhadap suatu isu dan menyepakati (consensus) bagaimana melakukannya, dengan tidak lupa memberi peran (tasks) mereka untuk terlibat secara langsung dalam memecahkan masalah tersebut. Apa yang menjadi janji-janji birokrat dalam menangani isu tersebut dapat dievaluasi dan dimonitoring secara bersama. Tinggal lagi tugas dan peran para politisi dan birokrat untuk menunjukkan sumberdaya (resources) yang memungkinkan sebuah isu dapat diselesaikan secara bersama-sama (Charles Perrow, 1979).

Cara lain untuk mengukur tingkat efektifitas kebijakan juga bisa dilihat dari tingkat sekolah. Kelas dan sekolah harus dijadikan cermin oleh birokrasi pendidikan bagaimana sebenarnya sistem pendidikan kita ditegakkan dan dijalankan. Karena itu kebebasan akademis dari para guru, kepala sekolah, siswa dan masyarakat harus tercermin kuat dalam program penguatan kapasistas guru dan sekaligus kapasitas peranserta masyarakat yang berkesinambungan. The primacy of teachers harus menjadi prioritas bukan hanya aspek kesejahteraannya, tetapi juga kapasitasnya. Karena tanpa kapasitas yang mumpuni para guru akan semakin terjebak pada rutinitas mengajar yang formal, di mana guru selalu ingin memaksakan prakonsepsi tertentu kepada pikiran para siswa tinimbang sebagai fasilitator yang akan membuat para siswa lebih kreatif dan terbuka (Hatch, White, \& Faigenbaum, 2005). 


\section{BIBLIOGRAFI}

Beyer, E. Landon and Apple, Michael W. (1998). The Curriculum: Problems, Politics, and Possibilities (second edition).

Deal, T. (1988). The Symbolism of Effective Schools. In A.Westoby (ed.). Culture and Power in Educational Organizations. Philadelphia: Open University Press.

Donahoe, T. (1997). Finding the Way: Structure, Time, and Culture in School Improvement. In M. Fullan (ed.). The Challenge of School Change. Illinois: Skylight Training and Publishing.

Finnan, C. (April 2000) Implementing School Reform Models: Why is it so Hard for Some Schools and Easy for Others? Paper presented at the meeting of the American Educational Research Association, New Orleans. (ERIC Document Reproduction Service No. ED446356.

Freiberg, H. J. (1998). Measuring school climate: Let me count the ways. Educational Leadership 56 (1), 22-26.

Fullan, M. (1991). The new meaning of educational change. New York: Teachers College Press.

Glaeser, Edward L. 2002. "The Political Economy of Hatred." Mimeo, Harvard University, August.

Goodlad, J. (1984). A place called school. San Francisco: McGrawHill.

Hansen, J. M. and Childs, J. (1998). Creating a school where people like to be. Educational Leadership 56 (1), 14-17.

Hargreaves, A. (1997). Cultures of teaching and educational change. In M. Fullan, Ed., The challenge of school change. Illinois: Skylight Training and Publishing.

Hargreaves, A. (1997). Introduction. In A. Hargreaves (ed.), Rethinking educational change with heart and mind: 1997 $A S C D$ yearbook. Virginia: Association for Supervision and Curriculum Development.

Hinde, E. R. (2002). Switching classes: Teachers 'conceptualizations of change in their professional lives. Unpublished doctoral dissertation. Arizona State University. 
Hollins, E. (1996). Culture in school learning: Revealing the deep meaning. New Jersey Lawrence Erlbaum Associates.

Kottler, J. (1997). What's really said in the teachers 'lounge: Provocative ideas about cultures and classroom? California: Corwin Press

Marshall, C., Mitchell, D., \& Wirt, F. (1989). Culture and education policy in the American states. New York: The Falmer Press.

McLaren, P. (1997). Schooling as a ritual performance. Boulder: Rowman \& Littlefield.

Peterson, K. and Deal T. (1998). How leaders influence the culture of schools .Educational Leadership 56 (1), 28-30.

Sarason, S. (1996). Revisiting the culture of the school and the problem of change, New York: Teachers College Press

Schweiker-Marra, K. (1995). Examining the relationship between school culture and teacher change. Paper presented at the meeting of the Eastern Educational Research Association, Hilton Head SC. (ERIC Document Reproduction Service No. ED41218.

Weiler, J. (1998). Success for all: A summary of evaluations. ERIC/ CUE Digest \#139 New York: ERIC Clearinghouse on Urban Education

Wirt, F. M., \& Kirst, M. W. (1989). The politics of education: Schools in conflict (2nd ed.). Berkeley, CA: McCutchan. 